\title{
Renal sympathetic denervation in patients with vasospastic angina
}

\author{
Lida Feyz, MD, ${ }^{\mathrm{a}}$ Maureen Henneman, MD, PhD, ${ }^{\mathrm{b}}$ Fred Verzijlbergen, MD, PhD, , c \\ Isabella Kardys, $\mathrm{MD}$, PhD, ${ }^{\mathrm{a}}$ Nicolas $M$. Van Mieghem, $\mathrm{MD}, \mathrm{PhD},{ }^{\mathrm{a}}$ and \\ Joost Daemen, MD, PhD \\ a Department of Cardiology, Thoraxcenter, Erasmus Medical Center, CA Rotterdam, The \\ Netherlands \\ b Department of Radiology and Nuclear Medicine, Erasmus Medical Center, Rotterdam, The \\ Netherlands \\ c Department of Radiology and Nuclear Medicine, Radboud University Medical Center, \\ Nijmegen, The Netherlands
}

Received Sep 13, 2018; accepted Dec 11, 2018

doi: $10.1007 / \mathrm{s} 12350-019-01598-y$

Background. Sympathetic overactivity has been linked to vasospastic angina (VSA), although the exact pathophysiology of VSA is poorly understood. The purpose of this study is to assess if renal sympathetic denervation (RDN) reduces cardiac sympathetic nerve activity with a subsequent beneficial effect on angina relief in patients with refractory VSA.

Methods and results. Cardiac sympathetic nerve activity was assessed prior to procedure and at 6 months post-procedure using iodine-123 labeled meta-iodobenzylguanidine ( ${ }^{123}$ I-MIBG) imaging. The Seattle Angina questionnaire (SAQ) was used to assess the degree to which the disease impacts quality of life. No significant change was observed in early HMR (pre-RDN: 2.74 [2.10 to 3.21] vs 6 months post-RDN: 2.57 [2.20 to 3.00]; $P=0.76$ ), and late HMR (pre-RDN: 2.56 [2.18 to 3.20] vs 6 months post-RDN: 2.36 [2.13 to 3.22]; $P=$ 0.22). Additionally, no change was seen in WR $(P=0.22)$. SAQ results revealed significant improvements in perceived physical limitation, angina frequency, and quality of life at 6 months $(P<0.05$ for all $)$.

Conclusion. RDN resulted in improvements in angina class and quality of life at 6 months in patients with refractory VSA. RDN, however, did not result in significant changes in cardiac sympathetic nerve activity as measured using ${ }^{123}$ I-MIBG. The latter observation should be considered with caution given the small sample size of this study. Larger studies are needed to assess this further. (J Nucl Cardiol 2020;27:2202-9.)

Key Words: Renal sympathetic denervation • vasospastic angina $\cdot$ MIBG $\cdot$ metaiodobenzylguanidine $\cdot$ quality of life

Electronic supplementary material The online version of this article (https://doi.org/10.1007/s12350-019-01598-y) contains supplementary material, which is available to authorized users.

The authors of this article have provided a PowerPoint file, available for download at SpringerLink, which summarises the contents of the paper and is free for reuse at meetings and presentations. Search for the article DOI on SpringerLink.com.
Reprint requests: Joost Daemen, MD, PhD, Department of Cardiology, Thoraxcenter, Erasmus Medical Center, P.O. Box 2040, 3000 CA, Rotterdam, The Netherlands; j.daemen@erasmusmc.nl $1071-3581 / \$ 34.00$

Copyright (C) 2019 The Author(s) 


\begin{tabular}{|ll|}
\hline \multicolumn{2}{|l|}{ Abbreviations } \\
24h & 24h ambulatory blood pressure \\
ABPM & measurement \\
CT & Computed tomography \\
HMR & Heart-to-mediastinum ratio \\
${ }^{123}$ I-MIBG & Iodine-123 labeled \\
& meta-iodobenzylguanidine \\
MRI & Magnetic resonance imaging \\
MBq & Megabecquerel \\
RDN & Renal sympathetic denervation \\
SNS & Sympathetic nervous system \\
VSA & Vasospastic angina \\
WR & Washout rates \\
\hline
\end{tabular}

\section{See related editorial, pp. 2210-2215}

\section{BACKGROUND}

Vasospastic angina (VSA) is a clinical syndrome that was first described by Prinzmetal et al. in 1959. ${ }^{1}$ Although the syndrome has been characterized by episodes of coronary artery vasospasm, the exact pathophysiology of spasms is poorly understood. While studies from the early ' 80 s and ' 90 s already demonstrated that both the sympathetic and parasympathetic nervous system are responsible for coronary vasomotion, more recent work demonstrated significant hyperactivity of the sympathetic nervous system (SNS) in patients with VSA as compared to healthy controls. ${ }^{2-4}$ The majority of VSA patients present with refractory angina; however, the disease appears not benign. Syncope and ventricular arrhythmias are the first clinical presentation in up to $40 \%$ of the cases and the risk for sudden death may be increased by up to $50 \% .{ }^{5-8}$ Current treatment options are mainly pharmacological and include the use of long-acting nitrates and calcium channel blockers, which showed to provide symptom improvement in 30 to $80 \%$ of the cases, respectively. ${ }^{9}$ Looking for more effective treatments, several small studies showed that surgical (cardiac) sympathetic denervation resulted in a significantly lower number of angina episodes and ST-segment deviations on 24h holter monitoring. ${ }^{10,11}$ In the present study, we hypothesized that renal sympathetic denervation (RDN), a percutaneous treatment that proved to significantly lower blood pressure and systemic sympathetic nerve activity in hypertensive patients, might provide additional angina relief in patients with VSA. In order to quantify the potential effect of RDN on cardiac sympathetic nerve activity, iodine-123-labeled metaiodobenzylguanidine $\left({ }^{123} \mathrm{I}-\mathrm{MIBG}\right)$ scintigraphy was used. $^{12,13}$

\section{METHODS}

\section{Study Population and Endpoints}

Between April 2013 and August 2016, a total of 10 consecutive patients with refractory VSA underwent RDN. Patients were eligible in case of refractory angina. Significant residual coronary artery stenosis was ruled out and patency of previously implanted stents was confirmed in all cases by recent coronary angiography. Coronary physiologic assessment using fractional flow reserve was used in case of intermediate lesions.

VSA was confirmed in case of spontaneous or methylergonovine-induced spasms with ST-segment changes and symptoms of chest pain in 6 out of 10 patients. In 4 patients, the diagnosis was based on the presence of recurrent episodes of non-exercise-induced angina, which resolved after sublingual nitrates and in the absence of significant atherosclerotic coronary artery disease.

Patients were screened for RDN and followed according to routine clinical practice. Work-up included $24 \mathrm{~h}$ ambulatory blood pressure measurement (24h ABPM), laboratory analysis, echocardiography, and CT $(\mathrm{N}=2)$, MRI $(\mathrm{N}=7)$ or renal duplex $(\mathrm{N}=1)$ to confirm renal artery eligibility.

Follow-up in the outpatient clinic at 1, 3, and 6 months post-RDN included 24h ABPM (at 3 and 6 months) and echocardiography (at 6 months). Renal function was assessed at baseline and at follow-up. Renal artery imaging was performed at 6 months to confirm renal artery patency.

For the purpose of this, study patients were not subjects to acts, neither was any mode of behavior imposed, otherwise than as part of their regular treatment. Therefore, according to Dutch law, written informed consent for study enrolment was obtained. This study was conducted according to the privacy policy of the Erasmus Medical Center and the Erasmus Medical Center regulations for the appropriate use of data in patient-orientated research, which are based on international regulations, including the Declaration of Helsinki. All patients consented to the use of their data for scientific research.

The primary efficacy endpoint was the change in cardiac sympathetic nerve activity as measured using ${ }^{123} \mathrm{I}-\mathrm{MIBG}$ imaging at 6 months post-RDN, as compared to pre-RDN (baseline). The primary safety endpoint was defined as the occurrence of cardiovascular death, stroke, major access site bleeding, and acute kidney injury or renal artery stenosis at 6month follow-up.

Secondary endpoints included the changes in Canadian Cardiovascular Society grading (CCS class), blood pressure (24h ABPM and office blood pressure), and heart rate. The Seattle Angina Questionnaire (SAQ) was used to assess the quality of life and signs and symptoms of angina. 


\section{${ }^{123}$ I-MIBG Scintigraphy Data Acquisition and Analysis}

${ }^{123} \mathrm{I}-\mathrm{MIBG}$ is a physiologic analog of norepinephrine and acts selectively on sympathetic nerve endings. By using cardiac neurotransmission imaging, global information about neuronal function can be expressed in early, but more specifically in late HMR (reflecting the storage regional distribution and release of ${ }^{123} \mathrm{I}-\mathrm{MIBG}$ ), with washout rate (WR) reflecting the neuronal integrity or sympathetic tone. ${ }^{14} \mathrm{In}$ order to block thyroid uptake of free radioactive iodide, 200 $\mathrm{mg}$ potassium iodide (10\% solution) was administered. After 30 minutes, $185 \mathrm{MBq}{ }^{123} \mathrm{I}-\mathrm{MIBG}$ was administered intravenously. Early and late (i.e., 15 minutes and 4 hours after tracer injection, respectively) anterior planar scintigraphic images were acquired for 10 minutes with a zoom factor of 1.0 and stored in a $256 \times 256$ matrix. Patients were imaged in a supine position with a dual head gamma camera (Symbia $\mathrm{T}$, Siemens, Erlangen, Germany), using a medium energy collimator. An energy window of $\pm 10 \%$ was symmetrically centered around the $159-\mathrm{KeV}$ 123I photo peak. Offline processing software (Hermes Medical Solutions Workstation) was used to draw a round region of interest (ROI) with fixed diameter over the upper mediastinum, below the thyroid gland (Figure 1). Additionally, a manual ROI over the heart was drawn, carefully excluding adjacent activity in the liver and lung. The left ventricular cavity was included in the myocardial ROI. The MIBG images were scored by a dedicated nuclear medicine specialist blinded to the timing of the scan. The HMR was computed by dividing the average number of counts within the cardiac ROI by the average number of counts within the mediastinal ROI. Calculation of WR was performed using the following formula (no correction for background): $\mathrm{WR}=\left(\mathrm{HMR}_{\text {early }}-\mathrm{HMR}_{\text {late }}\right) /\left(\mathrm{HMR}_{\text {early }}\right) \times 100 \% .^{15}$

\section{RDN Procedure}

Pre-procedurally, $100 \mathrm{IU}$ heparin $/ \mathrm{kg}$ was administered to achieve an active clotting time $>250$ seconds. All procedures were performed under conscious sedation. After administration of local anesthesia, common femoral artery access was achieved by an ultrasound-guided puncture and a 7-Fr sheath was then introduced. A 7-Fr guiding catheter was used to accommodate the Paradise ${ }^{\mathrm{TM}}$ RDN catheter (ReCor Medical, Palo Alto, CA). ${ }^{16}$ After smoothly engaging the renal arteries by using a no-touch technique with the help of a standard hightorque BHW coronary guidewire, selective renal artery angiograms were made. The Paradise ${ }^{\mathrm{TM}}$ system ablation catheter was then advanced over the BHW wire. The

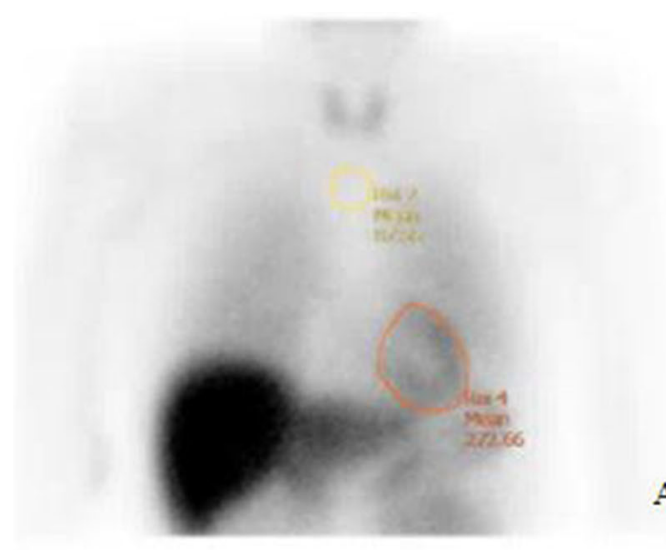

A1
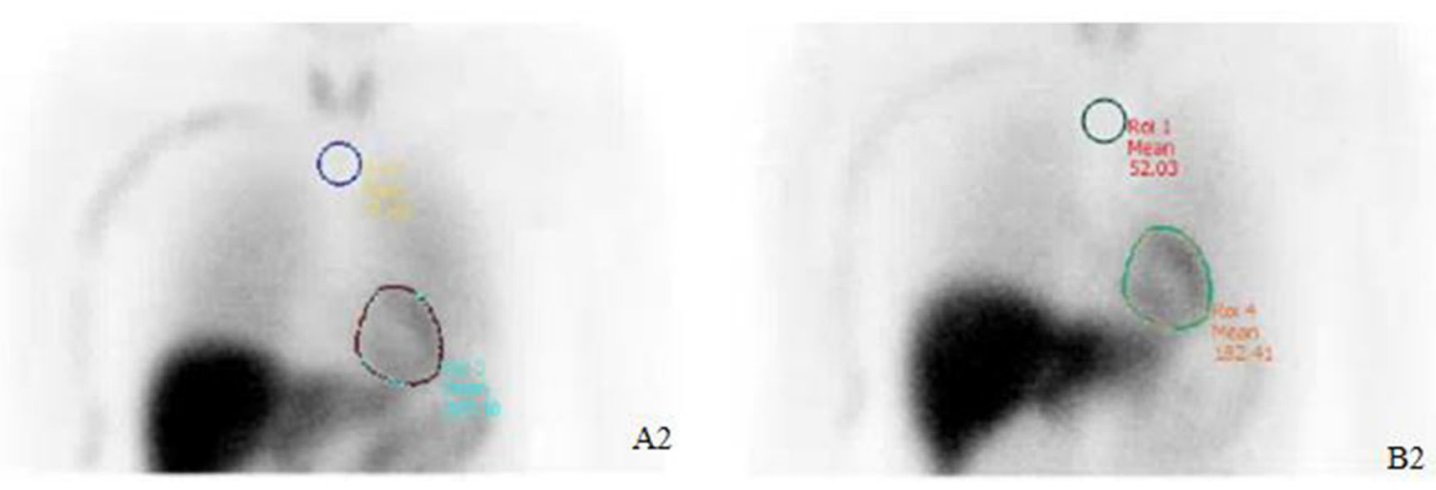

Figure 1. Example of MIBG image scoring with early and late HMR. Early HMR at baseline (A1) was 3.11 and changed to 3.35 at 6 months (A2), while late HMR at baseline was 3.23 (B1) and changed to 3.51 at 6-month (B2) follow-up. (A) 15 min after tracer injection, (B) $4 \mathrm{~h}$ after tracer injection. 
Paradise $^{\mathrm{TM}}$ catheter has a distal balloon which is pressurized by the Paradise system to a range of 1.5 to 2.0 ATM using sterile circulating water. The ultrasound transducer is located within the balloon (balloon diameters 5 to $8 \mathrm{~mm}$ ). A total of 2 to 3 ultrasound emissions of 6 to 10 seconds each were delivered per artery.

\section{Statistical Analysis}

Continuous variables were expressed as mean \pm standard deviation (SD). Continuous variables were compared using Student's t test. Categorical variables were expressed as percentages and were compared using the $\chi^{2}$ test or Fisher's Exact test when appropriate. Early and late HMR and WR were compared using the Wilcoxon signed-rank test. All statistical tests are 2-tailed. A $P$ value $<0.05$ was considered statistically significant. Statistical analysis was performed using SPSS statistical analysis (version 22.0).

\section{RESULTS}

\section{Study Population}

Mean age of the patients was $57 \pm 11$ years, $90 \%$ were male, and $90 \%$ were in CCS class III or IV. None of the patients had diabetes, and hypertension was present in $80 \%$ of the cases.

All patients were using anti-anginal therapy using long-acting nitrates (10/10) and calcium channel blockers $(8 / 10)$. Most patients had a history of prior coronary revascularization (Table 1 ).

\section{Primary Efficacy Endpoint}

${ }^{123}$ I-MIBG change. No significant change was observed in early HMR (pre-RDN: 2.74 [2.10 to 3.21] vs 6 months post-RDN: 2.57 [2.20 to 3.00]; $P=0.76$ ) and in late HMR (pre-RDN: 2.56 [2.18 to 3.20] vs 6 months post-RDN: 2.36 [2.13 to 3.22]; $P=0.22$ ). No significant change was observed in WR (pre-RDN: 15.0 [10.5 to 18.5] vs 6 months post-RDN: 13.0 [6.0 to 22.0]; $P=$ 0.22) (Table 2).

\section{Primary Safety Endpoints}

There were no peri-procedural complications. No adverse events including death, stroke, or renal artery stenosis occurred during 6-month follow-up. Renal function remained unchanged, and estimated glomerular filtration rate (eGFR) was $76 \pm 17 \mathrm{~mL} / \mathrm{min}$ pre-RDN vs $75 \pm 18 \mathrm{~mL} / \mathrm{min}$ at 6-month follow-up $(P=0.68)$.
Table 1. Baseline characteristics

\section{Total study population $\mathbf{N}=10$}

\begin{tabular}{|c|c|}
\hline Age, years & $57 \pm 11$ \\
\hline Male n, (\%) & $9(90)$ \\
\hline $\mathrm{BMI}, \mathrm{kg} / \mathrm{m}^{2}$ & $26.6 \pm 5.0$ \\
\hline eGFR, mL/min & $76 \pm 17$ \\
\hline \multicolumn{2}{|l|}{ Cardiovascular risk factors (\%) } \\
\hline Diabetes & $0(0)$ \\
\hline Hypertension & $8(80)$ \\
\hline Dyslipidemia & $9(90)$ \\
\hline Smoker, current & $3(30)$ \\
\hline Family history of premature CVD & $7(70)$ \\
\hline \multicolumn{2}{|l|}{ Cardiovascular history (\%) } \\
\hline Prior MI & $7(70)$ \\
\hline Prior PCI & $8(80)$ \\
\hline 24h ABPM, mmHg & $121 \pm 16 / 72 \pm 8$ \\
\hline Office BP, $\mathrm{mmHg}$ & $143 \pm 19 / 80 \pm 10$ \\
\hline Heart rate, bpm & $62 \pm 8$ \\
\hline \multicolumn{2}{|l|}{ Angina-grading scale } \\
\hline CCSI & - \\
\hline CCSII & $1(10)$ \\
\hline CCSIII & $8(80)$ \\
\hline CCSIV & $1(10)$ \\
\hline \multicolumn{2}{|l|}{ Echocardiographic parameters } \\
\hline LVEF, \% & $59 \pm 9.6$ \\
\hline LVEDD, mm & $50 \pm 6.1$ \\
\hline LVESD, mm & $34 \pm 4.9$ \\
\hline \multicolumn{2}{|l|}{ Pharmacological therapy, n (\%) } \\
\hline Nitrates, & $10(100)$ \\
\hline Calcium channel blockers ${ }^{\mathrm{a}}$ & $8(80)^{\mathrm{a}}$ \\
\hline Selective beta-blockers & $5(50)$ \\
\hline ACE/ATII & $8(80)$ \\
\hline Aspirin & $10(100)$ \\
\hline Diuretics & $4(40)$ \\
\hline Statins & $10(100)$ \\
\hline
\end{tabular}

Variables are presented in mean \pm SD or $\%$

$A B P M$, ambulatory blood pressure measurement; $B P$, blood pressure; $B M I$, body mass index; CCS, Canadian cardiovascular society grading of angina pectoris; CVD, cardiovascular disease; eGFR, estimated glomerular filtration rate; $M I$, myocardial infarction; $L V E F$, left ventricular ejection fraction; $\angle V E D D$, left ventricular end-diastolic diameter; $L V E S D$, left ventricular end-systolic diameter; PCI, percutaneous coronary intervention

${ }^{\mathrm{a}} \mathrm{N}=2$ were intolerant for calcium channel blockers

\section{Secondary Endpoints}

Outcome on angina and quality of life. CCS class improved significantly from $3.00 \pm$ 0.47 (pre-RDN) to $1.80 \pm 0.92$ at 6-month follow-up, $P$ $=0.005$. 
Table 2. Cardiac sympathetic nerve activity measured by ${ }^{123}$ I-MIBG pre- and 6 months postprocedure, expressed in median [IQR]

\begin{tabular}{llll}
\hline & \multicolumn{1}{c}{ Pre-RDN } & \multicolumn{1}{c}{ 6 months } & $\boldsymbol{P}$ \\
\hline Early HMR & $2.74[2.10-3.21]$ & $2.57[2.20-3.00]$ & 0.76 \\
Late HMR & $2.56[2.18-3.20]$ & $2.36[2.13-3.22]$ & 0.22 \\
WR & $15.0[10.5-18.5]$ & $13.0[6.0-22.0]$ & 0.22
\end{tabular}

Variables are presented in mean \pm SD

$H M R$, heart/mediastinum ratio; $W R$, washout rate

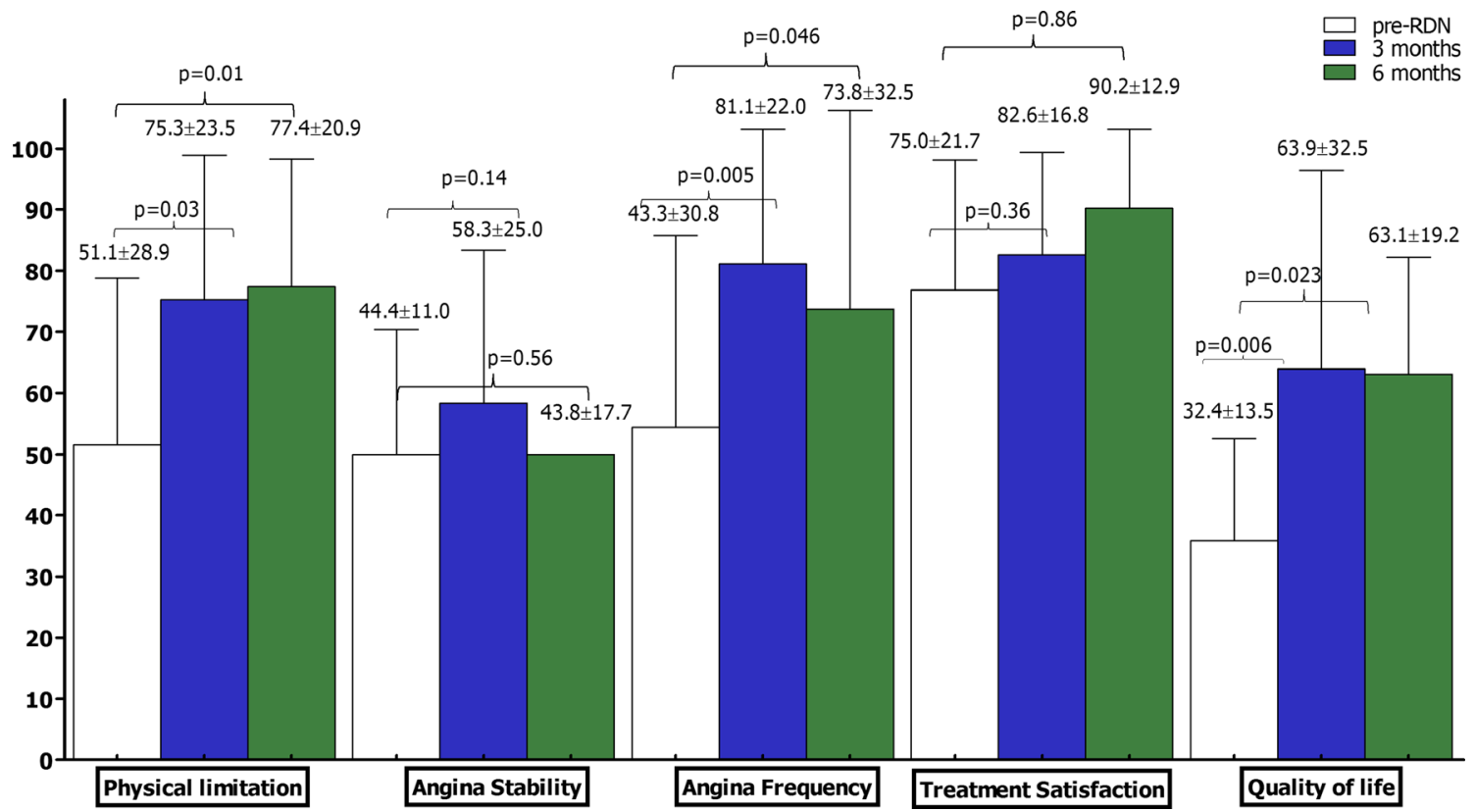

Figure 2. Seattle Angina Questionnaire (SAQ) SAQ scale (each scale is a score of 0 to 100 , wherein higher scores indicate better function or less angina/limitation and better quality of life).

The SAQ results showed significant improvements in 3/5 subscales at 3- and 6-month follow-up; patients were less limited in daily activities due to angina; angina frequency decreased significantly and quality of life improved as compared to pre-RDN. Angina stability and treatment satisfaction remained unchanged at 3- and 6month follow-up (Figure 2).

Blood pressure change. A numerical decrease in both office- and ambulatory BP at 6 months was found as compared to pre-RDN. Office BP changed from $143 \pm 19 / 80 \pm 10 \mathrm{mmHg}$ pre-RDN to $132 \pm 12 / 77 \pm$ $7 \mathrm{mmHg}$ at 6-month follow-up and $24 \mathrm{~h}$ ABPM decreased from $121 \pm 16 / 72 \pm 8 \mathrm{mmHg}$ to $112 \pm 8 / 70$ $\pm 7 \mathrm{mmHg}(P=\mathrm{ns}$ for all $)$.

Change in medication. During the course of the study, long-acting nitrates and calcium channel blockers were decreased or stopped in 4 patients, while dosages were increased in 3 patients (Figure 3 ).

\section{DISCUSSION}

This present single-center pilot study demonstrated that RDN might significantly improve quality of life at 6 months post-procedure. However, no significant change was observed in cardiac sympathetic nerve activity as assessed by ${ }^{123}$ I-MIBG at 6 months post-procedure.

The autonomic nervous system is a key regulator of coronary vasomotion and an imbalance between the sympathetic and parasympathetic nervous system has been reported in patients with VSA.,17,18 Provocation testing with parasympathetic agents such as acetylcholine or ergonovine can be performed in an attempt to confirm the diagnosis. ${ }^{19}$ In vitro, sympathetic agents like 

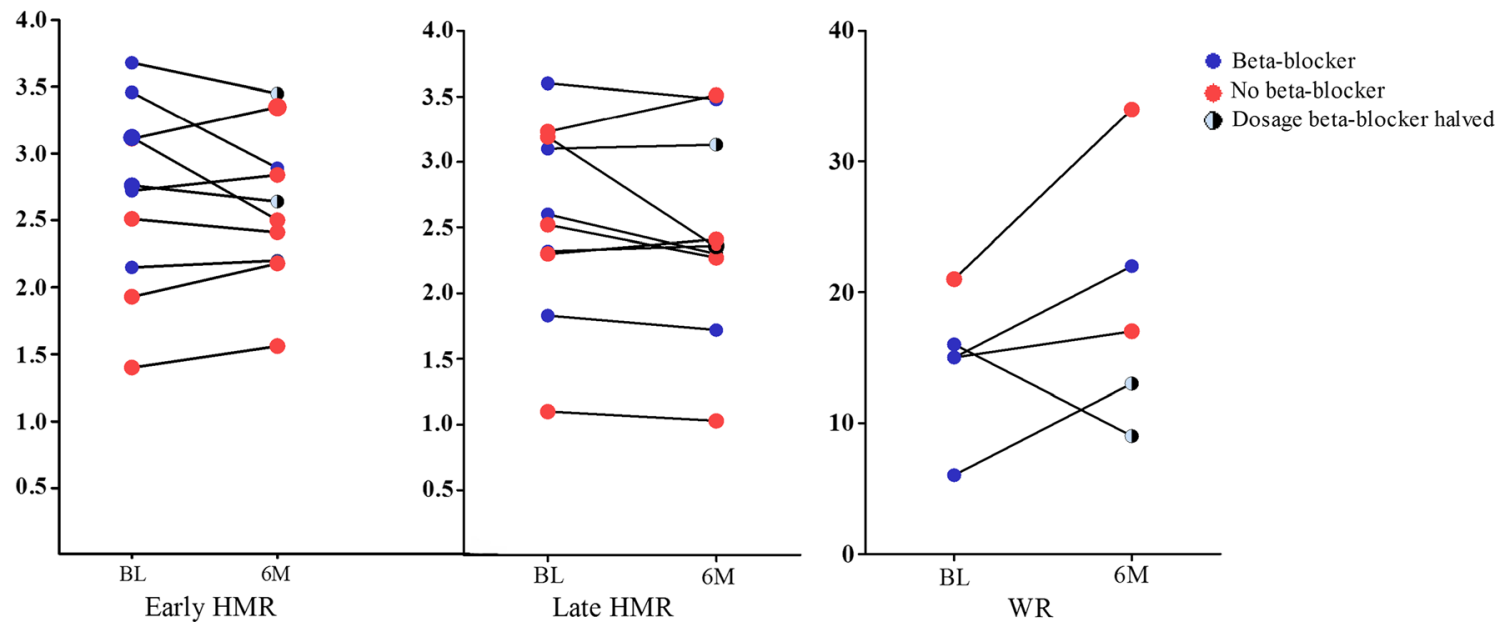

Figure 3. Change in early and late heart-to-mediastinum ratio (HMR), and washout rates (WR) at 6-month follow-up. Legend: 5 patients were off beta-blocker (red bullet) during the course of the study; 2 patients were on beta-blockers (same dose) at baseline and follow-up; 3 patients had betablockers at baseline and their dosage was halved $(\mathrm{N}=2)$ and $\mathrm{N}=1$ was stopped at 6 months. In 5 patients, no washout rate (WR) could be calculated at baseline or 6 months.

norepinephrine were used to test the severity of vasoconstriction or spasm. ${ }^{20}$

In the present study, we directly assessed cardiac sympathetic nerve activity by ${ }^{123}$ I-MIBG imaging, in line with previous work demonstrating the potential use of the technique in diagnosing VSA. ${ }^{21}{ }^{123} \mathrm{I}-\mathrm{MIBG}$ is a physiologic analog of norepinephrine and acts selectively on sympathetic nerve endings. By using cardiac neurotransmission imaging, global information about neuronal function can be expressed in early, but more specifically in late HMR (reflecting the storage regional distribution and release of ${ }^{123}$ I-MIBG); additionally, the WR reflects the neuronal integrity or sympathetic tone. ${ }^{14}$

${ }^{123}$ I-MIBG uptake is quantified by calculating an HMR after drawing regions of interest over the heart and mediastinum. Normal values for HMR and WR are $2.5 \pm$ 0.3 or greater and $20 \pm 10 \%$ or less, respectively. ${ }^{22}$ Little data are available on reference values in patients with VSA. Taki et al. reported higher WR in patients with VSA, probably due to increased sympathetic tone resulting in increased turnover of MIBG or impaired MIBG reuptake at the nerve endings. ${ }^{23,24}$ In addition, Arbab et al. showed a late HMR of $1.80 \pm 0.60$ in nine patients with VSA which was numerically lower as compared to healthy controls $(2.00 \pm 0.36) .{ }^{25}$ In the present study, pre-RDN HMR and WR were in line with previously published reference values for healthy control groups. Even in the cohort of patients with positive methylergonovine testing, mean late HMR was within the normal range. Our observations question whether HMR and WR in patients with VSA are truly significantly different than in healthy controls. Of note, several minor differences in imaging acquisition between this and other studies should be acknowledged such as the use of different collimators and radioactive compounds.

RDN has been studied since 2008 for its potential to control blood pressure in patients with therapy resistant hypertension, in which increased SNS activity has been hypothesized to play an important role. ${ }^{26}$ Only very recently, the results of several sham-controlled randomized trials demonstrated that the therapy, conducted using a radiofrequency ablation catheter, might significantly decrease blood pressure. ${ }^{27}$ At the same time, a series of studies were conducted to assess potential pleiotropic effects of RDN. ${ }^{28,29}$ In the present study, we attempted to further extend these findings in a cohort of VSA patients without residual regular therapeutic options. Given the limited options in objectively assessing the severity of signs and symptoms of these patients, we decided to further study the effect of RDN by using ${ }^{123}$ I-MIBG imaging. We hypothesized that post-RDN, late HMR would increase and WR would decrease as compared to pre-RDN. ${ }^{23,25}$ However, 6 months postRDN, we found no meaningful differences in both early and late HMR and WR. The latter thus again questions the role of the SNS in patients with VSA and the potential of RDN to decrease intra-cardiac sympathetic nerve activity.

Nevertheless, we found significant improvements in angina class and quality of life at 6 months along with a numerical decrease in BP. Following treatment with the Paradise ultrasound balloon catheter, mean systolic ambulatory blood pressure decreased with $9 \mathrm{mmHg}$ at 6 months. Although these figures did not reach statistical 
significance in the present small single-center study, the primary results of the RADIANCE SOLO trial assessing the safety and efficacy of the same device in a multicenter randomized sham-controlled setting showed a significant decrease in daytime $24 \mathrm{~h} \mathrm{ABPM}$ as compared to sham. ${ }^{30}$

\section{LIMITATIONS}

There are several limitations that should be taken into account. First, results were based on a small pilot study $(\mathrm{N}=10)$ and should be considered hypothesis generating. Using the results of the present study along with the findings of previous work by Arbab et al, a total of 70 patients would be needed to support that RDN results in a $20 \%$ increase in late HMR. Second, WR was calculated using one of the methods as described by Flotats et al., ${ }^{31}$ in which we used the actual heart counts for calculating WR, instead of ratios. Third, while the positive finding of a significant reduction in angina class could be interpreted as promising, a potential placebo effect of the treatment cannot be ruled out. In the recently published sham-controlled ORBITA trial, a sham procedure was able to significantly improve at least 3 subscales of the SAQ in patients with stable angina and significant coronary artery disease. ${ }^{32}$ Fourth, antianginal drug regimen was changed in $7 / 10$ of the patients [including an increase in nitrates $(\mathrm{n}=1)$ and diltiazem $(n=1)$ ]. The impact of medication on MIBG uptake should be taken into account. Jacobson et al. described that the MIBG uptake could be inhibited mostly by the use of beta-blockers such as labetalol. Less evidence is available on the MIBGinhibitory effect by calcium channel blockers. ${ }^{33}$ Furthermore, we acknowledge the fact that half of the patients were still using selective beta-blockers that were deliberately continued mostly due to the presence of a myocardial infarction in the past; in patients $(\mathrm{N}=3)$, beta-blockers were stopped or dosages changed during follow-up. However, also in patients in whom beta-blockers were either stopped or dosages were changed, no change in late HMR was found which was in line with results in patients without changes in drug regimen.

Finally, we cannot exclude the fact that apart from autonomic nervous system tone, multiple other alternative factors might play a role in triggering coronary spasms such as endothelial dysfunction or microvascular dysfunction. ${ }^{34,35}$

\section{NEW KNOWLEDGE GAINED}

The results in our study are promising and might fuel future discussion on the potential use of RDN in patients with vasospastic angina. Larger, randomized trials are needed to demonstrate the value of ${ }^{123}$ I-MIBG imaging post-RDN in patients with VSA.

\section{CONCLUSION}

RDN resulted in significant improvements in angina class and quality of life at 6 months in patients with refractory vasospastic angina. RDN did not result in significant changes in cardiac sympathetic nerve activity as measured using ${ }^{123} \mathrm{I}-\mathrm{MIBG}$.

\section{Disclosures}

Joost Daemen received institutional research support from Abbott Vascular, Medtronic, Boston Scientific, Acist, and Pie Medical as well as speaker and consultancy fees from Medtronic, Acist, and Pythagoras. Conflicts of interest for other authors are not declared.

\section{Open Access}

This article is distributed under the terms of the Creative Commons Attribution 4.0 International License (http://creativ ecommons.org/licenses/by/4.0/), which permits unrestricted use, distribution, and reproduction in any medium, provided you give appropriate credit to the original author(s) and the source, provide a link to the Creative Commons license, and indicate if changes were made.

\section{References}

1. Prinzmetal M, Kennamer R, Merliss R, Wada T, Bor N. Angina pectoris. I. A variant form of angina pectoris; preliminary report. Am J Med 1959;27:375-88.

2. Boudou N, Despas F, Van Rothem J, Lairez O, Elbaz M, Vaccaro A, et al. Direct evidence of sympathetic hyperactivity in patients with vasospastic angina. Am J Cardiovasc Dis 2017;7:83-8.

3. Yasue $\mathrm{H}$. Role of autonomic nervous system in the pathogenesis of Angina Pectoris. Arch Mal Coeur Vaiss 1983;76:3-6.

4. Lanza GA, Pedrotti P, Pasceri V, Lucente M, Crea F, Maseri A. Autonomic changes associated with spontaneous coronary spasm in patients with variant angina. J Am Coll Cardiol 1996;28:124956.

5. Feyz L, Wijchers S, Daemen J. Renal denervation as a treatment strategy for vasospastic angina induced ventricular tachycardia. Neth Heart J 2017;25:596-7.

6. MacAlpin RN. Cardiac arrest and sudden unexpected death in variant angina: Complications of coronary spasm that can occur in the absence of severe organic coronary stenosis. Am Heart J 1993;125:1011-7.

7. Yasue H, Takizawa A, Nagao M, Nishida S, Horie M, Kubota J, et al. Long-term prognosis for patients with variant angina and influential factors. Circulation 1988;78:1-9. 
8. Nishizaki M. Life-threatening arrhythmias leading to syncope in patients with vasospastic angina. J Arrhythm 2017;33:553-61.

9. Bottsilverman C, Heupler FA. Natural-history of pure coronaryartery spasm in patients treated medically. J Am Coll Cardiol 1983;2:200-5.

10. Betriu A, Pomar JL, Bourassa MG, Grondin CM. Influence of partial sympathetic denervation on the results of myocardial revascularization in variant angina. Am J Cardiol 1983;51:661-7.

11. Yoshida K, Inoue T, Hirakawa N, Node K. Endoscopic thoracic sympathectomy as a novel strategy for vasospastic angina refractory to medical treatments. J Cardiol 2008;52:49-52.

12. Carrio I. Cardiac neurotransmission imaging. J Nucl Med 2001;42:1062-76.

13. Donazzan L, Mahfoud F, Ewen S, Ukena C, Cremers B, Kirsch $\mathrm{CM}$, et al. Effects of catheter-based renal denervation on cardiac sympathetic activity and innervation in patients with resistant hypertension. Clin Res Cardiol 2016;105:364-71.

14. Wakabayashi T, Nakata T, Hashimoto A, Yuda S, Tsuchihashi K, Travin MI, et al. Assessment of underlying etiology and cardiac sympathetic innervation to identify patients at high risk of cardiac death. J Nucl Med 2001;42:1757-67.

15. Carrio I, Cowie MR, Yamazaki J, Udelson J, Camici PG. Cardiac sympathetic imaging with mIBG in heart failure. JACC Cardiovasc Imaging 2010;3:92-100.

16. Mauri L, Kario K, Basile J, Daemen J, Davies J, Kirtane AJ, et al. A multinational clinical approach to assessing the effectiveness of catheter-based ultrasound renal denervation: The RADIANCEHTN and REQUIRE clinical study designs. Am Heart J 2018;195:115-29.

17. Yasue H, Touyama M, Shimamoto M, Kato H, Tanaka S. Role of autonomic nervous system in the pathogenesis of Prinzmetal's variant form of angina. Circulation 1974;50:534-9.

18. Schwartz PJ, Stone HL. Tonic influence of the sympathetic nervous system on myocardial reactive hyperemia and on coronary blood flow distribution in dogs. Circ Res 1977;41:51-8.

19. Yasue H, Horio Y, Nakamura N, Fujii H, Imoto N, Sonoda R, et al. Induction of coronary-artery spasm by acetylcholine in patients with variant angina-possible role of the parasympathetic nervous-system in the pathogenesis of coronary-artery spasm. Circulation 1986;74:955-63.

20. Mohrman DE, Feigl EO. Competition between sympathetic vasoconstriction and metabolic vasodilation in canine coronary circulation. Circ Res 1978;42:79-86.

21. Sakata K, Shirotani M, Yoshida H, Kurata C. Iodine-123 metaiodobenzylguanidine cardiac imaging to identify and localize vasospastic angina without significant coronary artery narrowing. J Am Coll Cardiol 1997;30:370-6.

22. Patel AD, Iskandrian AE. MIBG imaging. J Nucl Cardiol 2002;9:75-94.

23. Taki J, Yasuhara S, Takamatsu T, Nakajima K, Tatami R, Ishise $\mathrm{S}$, et al. Value of iodine-123 metaiodobenzylguanidine scintigraphy in patients with vasospastic angina. Eur J Nucl Med 1998;25:229-34.
24. Sisson JC, Shapiro B, Meyers L, Mallette S, Mangner TJ, Wieland $\mathrm{DM}$, et al. Metaiodobenzylguanidine to map scintigraphically the adrenergic nervous system in man. J Nucl Med 1987;28:1625-36.

25. Arbab AS, Koizumi K, Takano H, Uchiyama G, Arai T, Mera K. Parameters of dynamic and static iodine-123-MIBG cardiac imaging. J Nucl Med 1995;36:962-8.

26. Krum H, Schlaich M, Whitbourn R, Sobotka PA, Sadowski J, Bartus K, et al. Catheter-based renal sympathetic denervation for resistant hypertension: A multicentre safety and proof-of-principle cohort study. Lancet 2009;373:1275-81.

27. Kandzari DE, Bohm M, Mahfoud F, Townsend RR, Weber MA, Pocock S, et al. Effect of renal denervation on blood pressure in the presence of antihypertensive drugs: 6-month efficacy and safety results from the SPYRAL HTN-ON MED proof-of-concept randomised trial. Lancet 2018;391:2346-55.

28. Brandt MC, Mahfoud F, Reda S, Schirmer SH, Erdmann E, Bohm $\mathrm{M}$, et al. Renal sympathetic denervation reduces left ventricular hypertrophy and improves cardiac function in patients with resistant hypertension. J Am Coll Cardiol 2012;59:901-9.

29. Jackson N, Gizurarson S, Azam MA, King B, Ramadeen A, Zamiri N, et al. Effects of renal artery denervation on ventricular arrhythmias in a postinfarct model. Circ Cardiovasc Interv 2017; 10:e004172.

30. Azizi M, Schmieder RE, Mahfoud F, Weber MA, Daemen J, Davies J, et al. Endovascular ultrasound renal denervation to treat hypertension (RADIANCE-HTN SOLO): A multicentre, international, single-blind, randomised, sham-controlled trial. Lancet 2018;391:2335-45.

31. Flotats A, Carrio I, Agostini D, Le Guludec D, Marcassa C, Schafers M, et al. Proposal for standardization of 123Imetaiodobenzylguanidine (MIBG) cardiac sympathetic imaging by the EANM Cardiovascular Committee and the European Council of Nuclear Cardiology. Eur J Nucl Med Mol Imaging 2010;37:1802-12.

32. Al-Lamee R, Thompson D, Dehbi HM, Sen S, Tang K, Davies J, et al. Percutaneous coronary intervention in stable angina (ORBITA): A double-blind, randomised controlled trial. Lancet 2018;391:31-40.

33. Jacobson AF, Travin MI. Impact of medications on mIBG uptake, with specific attention to the heart: Comprehensive review of the literature. J Nucl Cardiol 2015;22:980-93.

34. Bugiardini R, Pozzati A, Ottani F, Morgagni GL, Puddu P. Vasotonic angina: A spectrum of ischemic syndromes involving functional abnormalities of the epicardial and microvascular coronary circulation. J Am Coll Cardiol 1993;22:417-25.

35. Bugiardini R, Bairey Merz CN. Angina with "normal" coronary arteries: A changing philosophy. JAMA 2005;293:477-84.

Publisher's Note Springer Nature remains neutral with regard to jurisdictional claims in published maps and institutional affiliations. 